\title{
UNA LECTURA DE LA AUTORIDAD A PROPÓSITO DE TRES REGISTROS DE LA EXPERIENCIA DE MUJERES CADETES EN LA ESCUELA MATRIZ DEL EJÉRCITO DE CHILE
}

\author{
Claudia Pérez Bravo ${ }^{1}$
}

\section{Resumen / Abstract}

El presente artículo se propone analizar cómo la autoridad atraviesa distintos registros en la experiencia de las cadetes de la Escuela Militar de Chile a partir de tres escenarios: el ingreso, la permanencia, y las posibilidades de ejercicio de la profesión. Para ello, utiliza tres claves analíticas que permiten mostrar las distintas aristas que reviste la autoridad en el marco de esta experiencia. Estas son la de Revault D’Allonnes (2008) quien hace una lectura de la autoridad en la trama del tiempo. la propuesta de Gadamer (1997) quien pone en valor el acto de reconocimiento en contraposición al de obediencia, y la de Bourdieu (2005) que propicia una mirada de la autoridad entrelazada al poder en el marco de la dominación.

Palabras clave: autoridad, instituciones militares, mecanismos de dominación.

A READING OF AUTHORITY IN CONNECTION WITH THREE RECORDS FROM THE EXPERIENCE OF FEMALE CADETS AT THE ARMY MILITARY SCHOOL OF CHILE

This article analyzes how the authority goes through different records in the experience of cadets of the Military School of Chile from three scenarios: the entry, stay, and the possibilities of exercising the profession. It uses three analytical keys that display the different edges of authority during this experience. These are the of Revault D'Allonnes (2008) who gives a reading of authority in the current of time, Gadamer's proposal (1997) who places value the act of recognition as

1 Universidad Academia de Humanismo Cristiano. E-mail: claudia.perez.bravo@gmail.com 
opposed to obedience, and that of Bourdieu (2005), who put the authority in his relation to power and domination.

Keywords: authority, military institutions, mechanisms of domination

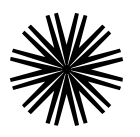

\section{Introducción}

Una pregunta inaugural para acercarnos y comprender qué es la autoridad, es saber si existe algo que le defina de modo central, o bien son los campos específicos en que surge los que van modelando su significado, naturaleza y ejercicio.

Entre quienes se han inclinado por la primera opción, la autoridad se ha pensado como una cuestión íntimamente ligada al poder (Weber, 1964; Arendt, 1966; Renaut, 2004; Revault d'Allonnes, 2008). Sin embargo, esta asociación entre poder y autoridad, no ha estado exenta de tensiones, principalmente porque traza una línea muy difusa entre la regulación y la dominación.

Arendt ha resuelto esta tensión entendiendo que la autoridad solo existe si su reconocimiento no se soporta en la coacción física o la persuasión. En esta clave, la autoridad funciona como un mecanismo fundante de lo político que permite el surgimiento de la comunidad y es condición de la libertad. Su origen etimológico, "autoritas", no remite al poder, sino al verbo "augere", significando entonces el aumento o, lo que hace crecer (Arendt, 1966). Este antecedente, posteriormente ha sido retomado por Revault d'Allones (2008) para pensar la autoridad como el poder de los comienzos, es decir, como lo que permite instituir lo social, asignándole a la autoridad una capacidad fundadora y regulativa. En este caso, la autoridad se justifica como aquello que permite la coordinación social.

Distinto ha sido el tratamiento que ha realizado Max Weber, uno de los autores que da origen al estudio del concepto. En el marco de su reflexión sobre las formas de dominación introduce la noción de autoridad en tanto contracara del poder (Weber, 1964). En este caso, la autoridad sería un instrumento de regulación en el ejercicio de dominación, asentado en la legitimidad que se le confiere. Al respecto, el autor deslinda tres tipos ideales de autoridad de acuerdo 
a la fuente de legitimidad que éstas reclaman: racional-legal, tradicional y carismática. La autoridad es una relación social que se expresa como mandoobediencia y supone una reciprocidad de sentido entre las partes. Las razones para obedecer quedan ligadas a los principios de legitimación que subyacen a este acto. Con ello se establece que la obediencia es algo más que el efecto de imposición del poder, es más bien la creencia que los individuos asignan a la capacidad de mando (Geicsnek, 2012).

Ahora bien, si nos aproximamos a una visión de la autoridad mediada por distintos ámbitos sociales - políticos, jurídicos, institucionales, entre otros- que nutren su contenido y vitalizan su significación, se vuelve evidente la afirmación de que existen muchos tipos de autoridad, y que la autoridad se posee y ejerce de modos diversos (Araujo, 2012). La obviedad de esta afirmación, sin embargo, oculta su relevancia para un análisis empírico del fenómeno. Es precisamente porque la autoridad es, como postula Kojève (2006), una forma de relación social y por tanto un producto social construido colectivamente en espacios y tiempos específicos, que es de importancia atender y ponderar, a través del análisis de las experiencias en donde circula y se despliega, su naturaleza variable.

Este trabajo propone relevar que la autoridad es una clave interpretativa que se extiende a los más diversos ámbitos sociales, y que una lectura que contemple esta perspectiva nos habilita para realizar un análisis que, sin perder de vista las relaciones mando-obediencia, involucra otras entradas que permiten matizar la reflexión del fenómeno.

En lo que sigue me propongo analizar cómo la autoridad atraviesa distintos registros en la experiencia de las cadetes de la Escuela Militar de Chile, a partir de tres escenarios: El ingreso, es decir, el por qué han decidido seguir la carrera; la permanencia, referido al proceso de exposición a diversos mecanismos de formación y exigencias de comportamiento; finalmente, los límites en el ejercicio de la profesión. Para ello me apoyaré en una selección de evidencias empíricas de un trabajo previo². Además, utilizaré, tres claves analíticas que, a pesar que difieren tanto en objeto como en perspectiva permiten mostrar las distintas aristas que reviste la autoridad en el marco de esta experiencia. Estas son la de Revault D'Allonnes (2008), quien hace una lectura de la autoridad en la trama del tiempo; la propuesta de Gadamer

2 Pérez, Claudia. "Construcción identitaria de las mujeres en el sistema de educación del Ejército de Chile". Tesis para optar al grado de Licenciada en Sociología. Universidad Academia de Humanismo Cristiano. 
(1997), quien pone en valor el acto de reconocimiento en contraposición al de obediencia; y la de Bourdieu (2005), que propicia una mirada de la autoridad entrelazada al poder en el marco de la dominación. Lo anterior será expuesto para cada escenario en este ese mismo orden.

El propósito principal del artículo es ilustrar los mecanismos de transmisión, ejercicio y (re)producción de la autoridad situando la discusión en la especificidad de las relaciones de género que experimentan las mujeres cadetes en este contexto institucional particular, utilizando para ello tres enfoques teóricos que enfatizan distintos ángulos de las experiencias de la autoridad y por tanto su carácter situado.

Antecedentes de la incorporación de las mujeres al Ejército de Chile

En los últimos decenios nuestro país ha progresado significativamente en la igualdad entre hombres y mujeres. La existencia de un nuevo marco de leyes y políticas que promueven la mayor legitimidad que ha alcanzado la igualdad de género en la sociedad, ha repercutido en una mayor igualación de las capacidades y oportunidades de hombres y mujeres (PNUD, 2010). La reciente incorporación de mujeres a las fuerzas armadas como parte de la organización, que implica la apertura de las escuelas militares, es un indicador muy significativo, puesto que permite dimensionar los diversos avances en materia de igualdad de género en todos los ámbitos de la vida pública, especialmente en educación postsecundaria.

La experiencia de inclusión de mujeres a las fuerzas armadas en Latinoamérica, a través de las escuelas militares, se relaciona fuertemente con el retorno a gobiernos democráticos. El proceso de incorporación se desarrolla de manera heterogénea, tanto en referencia a las particularidades de los contextos sociopolíticos de cada país, como a las distintas ramas (terrestre, naval y aérea), escalafones y especialidades. En este último punto, la norma general es la exclusión de mujeres de las especialidades de combate directo, a excepción de Uruguay. Esta tendencia general también es observada en países como Estados Unidos y el Reino Unido donde la incorporación de mujeres tiene larga data (Lucero, 2009).

En Chile, el ingreso a cualquiera de las organizaciones militares se realiza necesariamente a través de un modelo educativo propio y exclusivo a 
cada una de ellas. En específico, el sistema educativo del ejército para la carrera de oficiales contempla tres niveles de estudio.

El primero de ellos marca la entrada a la carrera militar y corresponde al proceso de formación básica, donde se proporcionan las capacidades militares asociadas al mando, conducción de pequeñas unidades, sistemas de armas y administración. El segundo nivel de formación es coextensivo al primero, y tiene como finalidad la especialización en alguna de las áreas de tácticas al interior de la organización. El proceso de formación superior corresponde al tercer nivel educacional, en el que se desarrollan programas de posgrado en distintas disciplinas de la ciencia militar.

En el presente trabajo nos centramos en el Ejército de Chile, en el cual se puede apreciar una integración escalonada en el tiempo. Desde 1974 con la apertura de la Escuela de Servicio Auxiliar Femenino (ESAFE), las mujeres están presentes en la organización. En esta primera etapa, como indica Villalobos (2007) las funciones asignadas a las mujeres no eran propiamente militares, sino de apoyo administrativo en temas financieros, de personal, secretaría y manejo de documentos. Luego, en 1995, en lo que podríamos llamar una segunda etapa, ingresan mujeres a la Escuela Militar con un programa académico de dos años. A partir de 1999 se expanden sus funciones al incorporarse mujeres en las áreas de apoyo logístico de material de guerra e intendencia. Una tercera etapa comienza en 2003 cuando se produce un importante cambio al abrirse las posibilidades para las oficiales de integrar las Armas de Apoyo de Combate, de Artillería, Ingenieros y Telecomunicaciones, ampliando así los ámbitos de desempeño del personal femenino. Actualmente pueden optar a especializaciones secundarias, de acuerdo con las necesidades institucionales, cumpliendo con los requisitos necesarios, incluyendo algunas especializaciones de combate (Libro de la Defensa Nacional, separata de actualización $\left.n^{\circ} 28,2005\right)$.

\section{Aclaraciones metodológicas}

La línea narrativa que propone la investigación cualitativa ocupa técnicas que permiten el acceso a la subjetividad a través del lenguaje, junto con un análisis mediante el método hermenéutico caracterizado por la comprensión e interpretación del mundo simbólico y cultural que los individuos plasman en sus acciones (Vieytes, 2004). Ambas características permiten esclarecer, mediante el relato protagónico, cómo los individuos/as se relacionan con su 
entorno, viven o experimentan cambios en sus hábitos y costumbres, así como las transformaciones que generan para adaptarse a nuevos contextos. En suma, cómo se relacionan y cómo sus interacciones dan cuenta de una reelaboración constante del entramado de relaciones que generan distintas experiencias y su naturaleza variable en distintos contextos.

Como instrumento de recolección de información se utiliza la entrevista en profundidad semiestructurada. Con la elección de esta técnica se pretende obtener un relato "experienciado", en el que se da cuenta de las prácticas pasadas y presentes que recrean las entrevistadas en relación a las relaciones de autoridad en el contexto militar.

Es importante mencionar que se abordó a las entrevistadas mediante la institución respectiva. Esta solicitó tener claro el número de entrevistas y su duración con el fin de coordinar los permisos, por lo cual se define un número de ocho entrevistas, dos por cada nivel de estudio de primero a cuarto año.

Por otra parte, aun cuando existen tres compañías, y en todas ellas participan mujeres, por decisión de la organización, todas las entrevistadas pertenecen a la misma unidad ( $1^{\text {a }}$ Compañía). Se contó con diversos criterios de diferenciación relativos, principalmente, a la procedencia familiar y territorial.

\section{Autoridad, tiempo e institución}

Miryam Revault d'Allonnes (2008) nos ofrece un análisis de la autoridad situada en una perspectiva temporal. Con esta inscripción, es el tiempo el que tiene fuerza de autoridad y ésta se despliega tanto hacia atrás como hacia adelante articulando la idea que pasado y futuro autorizan nuestras acciones presentes. El tiempo toma fuerza de autoridad encarnado en la institución: reconoce a la autoridad una capacidad habilitadora en tanto institucióninstituyente de lo social. La autoridad es entonces un acto de producción "el poder que hace surgir, que da existencia (...) la autoridad es el poder de los comienzos" (p. 73).

En rigor, desde esta entrada analítica, la autoridad no es desmentida como ejercicio de poder, pero el poder que se ejerce no busca dominar sino crear, habilitar, instituir lo social. La matriz temporal -su espacio de circulación-es 
lo que permite aclarar, para la autora, el que la autoridad no se confunda con el poder (dominación sobre) y por ello no se limite a ser su instrumento.

Eliminada la triada poder-autoridad-dominación, no es posible soslayar el elemento no simétrico de la autoridad, el cual ha sido aparejado con la dominación expresada en la jerarquía, puesto que la caracteriza y constituye. Sin embargo, la asimetría recibe un significado distinto en cuanto la superioridad de la autoridad de quien la detenta y, por tanto, el posicionamiento en lo alto de jerarquía de quien la encarna proviene de una instancia que lo excede ya sea como precedencia o bien como proyecto, cuestión que permite reconocer en relación a su justeza, según la autora, la legitimidad que la sustenta. Así es como la autoridad surge desde un exceso, es decir, de una exterioridad posible de situar en la matriz temporal y, por tanto, no se vive como dominación sino como capacidad habilitadora y legitimadora.

Ahora bien, como se ha planteado el fenómeno de la autoridad no es unívoco, y un análisis más acabado de ella implica pensarla dentro del entramado de relaciones que la generan. Se debe, entonces, y así es como lo propone la autora, realizar un desplazamiento desde la autoridad a la autorización, lo que implica afirmar que la autoridad es autorizada, esto es, se autoriza tanto a quien se le reconoce autoridad como a sus actos presentes, ya sea tanto por la preeminencia del pasado - situado arriba o atrás- como por el exceso del futuro -situado arriba y adelante- como proyecto. Puesto que la experiencia permite precisar su naturaleza variable es al verbo a lo que es preciso atender. La autoridad transformada en autorización permite emprender la búsqueda de aquello que justifica y que la legitima en cada uno de los campos, experiencias y circunstancias en que surgen relaciones de autoridad.

La visión de la autoridad que nos entrega Miryam Revault d'Allonnes (2008), es una clave de lectura interesante para analizar cómo la autoridad atraviesa lo que hemos definido como un primer escenario de la experiencia de las cadetes de la Escuela Militar de Chile: el ingreso en el eje del tiempo: pasado-futuro.

El ingreso en el eje del tiempo: pasado-futuro

En el primer escenario - el ingreso- hago referencia a las modalidades que asume la autoridad que se activa en el discurso de las cadetes, en referencia 
al por qué optan seguir la carrera militar. De lo que se trata es de mostrar cómo la autoridad es movilizada en dos direcciones, a propósito de la distinción entre quienes poseen una vinculación previa, y aquellas cadetes que no estaban vinculadas a la organización con anterioridad a su ingreso. La primera, en relación a la continuación, el traspaso del oficio, expresado como un legado, y la segunda en torno al proyecto.

En la primera dirección -el traspaso del oficio- se puede distinguir como soporte o fuente de autoridad-autorización, la tradición familiar. Veamoslo con mayor detalle a través de un relato:

"Porque mi papá siempre quiso que postulara a la Escuela, o sea, que orgullo más grande para él que sus tres hijos pertenezcan al Ejército... quiero ser militar, porque quiero seguir la tradición familiar (...) mi papá me dice que por mis venas corre sangre con prestigio... como que siento que tengo algo en mi espalda" (Cadete $1^{\circ}$ ).

El ejercicio de la autoridad se muestra aquí como un acto de enunciación no explícito, la autoridad no es dirigida directamente como una orden, sino como mandato que expresa el deseo del padre, la autoridad paterna, pero más concretamente involucra y da cuenta cómo el peso de la tradición familiar se convierte en fuente de autorización, es decir, es lo que autoriza por su exterioridad y precedencia a la autoridad del padre.

A su vez, en la medida en que este mandato queda definido por la carga de responsabilidad de no quebrar el "legado" que implica pertenecer a una familia con referentes militares cercanos, la cuestión de ser fiel o auténtico a sí mismo se mezcla con ser auténtico y fiel respecto a las solidaridades familiares, esto es, cumplir la expectativa de formar parte de una unidad, en este caso familiar, activando la transmisión generacional, por un lado, y por otro, respondiendo al deseo del padre de heredar este capital irrenunciable. Así es como el presente de su acción, su decisión de ingresar a la Escuela Militar, se autoriza y soporta sobre una herencia que es preciso reivindicar. Desobedecer el mandato de la tradición implica, de algún modo, desconocer el "linaje” y autoexcluirse del "nosotros familiar". Por tanto, en estos casos, la autoridad venida de la tradición familiar, como un poder latente y acrecentador, no 
puede ser desconocida. En breve, este acto les permite conservar la tradición familiar revitalizando una especie de origen fundacional.

Ahora bien, y tal como apunta Miryam Revault d'Allonnes (2008), la precedencia de la autoridad no se sitúa solamente en el pasado. $\mathrm{Si}$, como se ha señalado, la autoridad esta temporalmente inscrita es necesario considerar la dimensión futura en que se moviliza-autoriza.

En este propósito, es que distinguimos una segunda dirección -en torno al proyecto- en la cual y en distinción a la movilización anterior, no hay pretensión de dar continuidad a la tradición rehabilitando una autoridad, dado que en sus propias biografías no disponen de este recurso. Tampoco es posible inscribirlas en el signo de la pérdida de autoridad, sino más bien resulta pertinente situarlas en el signo del vacío. Lugar vacío que implica la exigencia de un inicio, asumiendo por cuenta propia la afirmación de sí orientada hacia el futuro. Con lo cual distinguimos como segunda modalidad para esta entrada: la autorización del futuro, expresada en uno de los relatos:

"... quería algo que me diera algo diferente, experiencias, vivir cosas que no iba a poder vivir normalmente en una carrera profesional... Porque yo lo que quiero, es cuando yo sea viejita "decir <yo hice todo esto>... con lo que me entrega la formación militar, yo voy a poder decir, cuando quizás sea el último día de mi vida, poder mirar atrás y decir <hice esto, o viví realmente>" (Cadete $\left.3^{\circ}\right)$.

El soporte o fuente de autoridad-autorización es la preeminencia de lo que está por venir. En la medida en que en la elección de incorporase a la Escuela Militar se activan estrategias creativas en torno a la construcción de un proyecto, sus decisiones y acciones del presente son autorizadas desde el futuro. Asegurar que las decisiones del presente logren orientar el rumbo de lo que se espera en el futuro, no es solo organizarlo en su función para asegurarlo, sino, y esto es lo que interesa de relevar, es reconocer su preeminencia, en tanto fuente de autoridad.

A su vez, de algún modo, aquello que orienta la acción y le dota de sentido es un deber ser alojado en el futuro. Aquello que es movilizado por la autoridad en este caso, es un deber ser protagónico, es ella quien tiene las competencias para ser el fundamento de su destino y la autora de sus actos. Y, en este sentido, es un futuro que le corresponde anticipar, forjar y proyectar 
bajo la impronta de su propio arbitrio autorizándose a sí misma. La autoridad del futuro, esta otra preeminencia, le autoriza a autorizarse.

\section{El reconocimiento: una de las claves de la autoridad}

Lo que funda una relación de autoridad para Gadamer (1997), y con lo cual se distingue de las formas de sujeción, no es la obediencia de lo que se manda sino el acto de reconocer la capacidad de quien la detenta. Así es como la autoridad se funda y verifica no en el cumplimento o acatamiento de órdenes, sino en el reconocimiento de una mayoridad en el otro. En este marco, y esto es un aporte para su comprensión, la autoridad ya no está más cifrada en la obediencia o, al menos, en la obediencia ciega o mecánica, esto es, como si el mandato se convirtiera en una máxima de conducta cerrando el espacio para la propia opinión y valoración de lo que se manda a obedecer (Weber, 1964).

Con la propuesta de Gadamer la asociación entre autoridad-arbitrariedad se diluye. Su lectura interesada mayormente en el acto de adjudicación y menos en el efecto de su ejercicio lo permite. Así es como al descentrar el análisis de autoridad de la díada mando-obediencia, al tiempo que pone de relieve el acto de adjudicación mediante el reconocimiento de la superioridad del otro, implica advertir que la obediencia o consentimiento no necesariamente procede de ejercitar de un modo autoritativo la autoridad.

$\mathrm{Si}$, como sostiene el autor, las relaciones de autoridad se vuelven efectivas y legitimas a través del reconocimiento, ya que este acto introduce la razón y el juicio de quien lo realiza (quien reconoce racionalmente a otro como autoridad le concede primacía en relación a sí mismo y a sus propios límites), la aceptación de la autoridad entraña un acto reflexivo. Así también, si se acepta que la dimensión del reconocimiento aminora el carácter impositivo contenido en la jerarquía que se instaura, ya que requiere desde un principio una disposición racional de quien reconoce (a partir del otro y en confrontación a sí mismo su lugar en la relación), es posible plantear que el reconocimiento procura a un mismo tiempo concesión y aceptación más que simple obediencia.

Un aporte central que se desprende en esta propuesta es que contraviene el fundamento de la autoridad sustentada sólo en la posición que manda y encuentra como resultado obediencia. Como hemos visto, su punto de mayor 
fortaleza se sitúa principalmente en la capacidad reflexiva de quien otorga autoridad a otro, por un parte, y por otra, a partir de la capacidad y valía de quien la adquiere. Ambos aspectos ponen de relieve el carácter relacional de la autoridad. Sin embargo, es preciso advertir que este énfasis reduce la comprensión de las relaciones de autoridad porque les condiciona fuertemente a la tenencia de atributos reconocidos como personales. Una atenta lectura de las relaciones de autoridad debería incluir distintos soportes.

\section{La permanencia: jerarquía y exigencias de comportamiento}

En la permanencia en la institución, referida al proceso de exposición a diversos mecanismos de formación y a exigencias de comportamiento, la autoridad expresada en la díada mando-obediencia es una experiencia masiva en esta realidad institucional. El elemento no simétrico de la autoridad (A rendt, 1996) que ha sido aparejado con la dominación de la jerarquía (Weber, 1964) aparece en las relaciones institucionales armadas de modo contundente.

Sin embargo, lo que aquí deseo analizar es la función que juega el reconocimiento, primero en el proceso de internalizar -pese a la sospecha permanente- el respeto a la autoridad estatuida por la jerarquía, y segundo, la importancia que asume la proyección y reconocimiento de una imagen de autoridad como una carta de funcionamiento organizacional.

La organización militar chilena de tipo institucional (Moskos, 1982) articula un conjunto de elementos constituyentes en su ordenamiento, entre ellos, el régimen de interacción jerárquico, el cual funciona como uno de los descriptores centrales de la práctica institucional del sistema, definiendo mandos y posiciones escalonadas y concatenadas. En base a este régimen de interacción, se inscriben las exigencias de autoridad y obediencia como partes de un modelo de disciplinamiento: "La interiorización de la disciplina forma parte del ritual $y / o$ entramado teatral de su representación: se originan actitudes encaminadas a obedecer las órdenes, siguiéndolas de una manera uniforme; las órdenes se cumplen de una manera metódica y acritica. La acción uniformada y ritualizada es una componente fundamental en el comportamiento militar, en consonancia con ese desarrollo jerarquizado y disciplinario"(Molina, 1996: 199).

La autoridad sustentada por la jerarquía en este marco institucional, como se sabe, proviene de este orden jerárquico estricto que permite consolidar 
los idearios del mérito y la imparcialidad y así también coordinar sus acciones. En este contexto, la obediencia se concreta en función de la posición en la estructura, puesto que es de la misma desde donde se extrae la legitimidad de su exigencia. Como nos lo recuerda Weber el tipo de legitimidad de índole racional se asienta en la creencia en la legalidad del orden (Weber, 1964). Sin embargo, como lo declara una de las cadetes respetar el rango o la antigüedad, el orden jerárquico impersonal es, al menos, problemático:

"Mi primer año fue complicado en el sentido que hay personas que son más antiguas que tú, pero que son menores que tú en edad, entonces eso me costó a mi bastante, hasta el día de hoy me cuesta mucho que alguien menor que yo me mande, eso como que todavia no lo tolero mucho, como que nunca me ha gustado, como que a eso le tengo rechazo todavia, pero uno después empieza a vivir con eso" (Cadete $2^{\circ}$ ).

Desde este relato es posible comprender que una autoridad encuentra mayor verificación a través del registro del reconocimiento que desde el de la obediencia. Es el primero -el reconocimiento- el que juega un rol determinante en formular su legitimidad. Pese a ello se obedece, pero este acto abre una lectura de la autoridad en clave de sometimiento, activándose, con contundencia, el poder y la arbitrariedad que caracteriza a un régimen de interacción jerárquico (Martuccelli, 2007). En este contexto, la autoridad termina afirmándose de modo autoritativo, principalmente porque la jerarquía que sostiene el acto, se trata de una jerarquía "desnuda" y despersonalizada que da como resultado una relación en donde quienes ocupan las posiciones de mayor poder de mando no siempre alcanzan las cualidades personales o aquellas tradicionalmente exigidas por los otros para reivindicar autoridad (en este caso la experiencia atribuida a la edad). En este sentido es posible colegir que reconocer a una autoridad, consintiendo o no, implica movilizar componentes subjetivos y que para ser reconocido como autoridad el status no es un elemento que por su propia valía permita originar legitimidad.

Por su parte, es posible pensar la proyección de una imagen de autoridad como una carta de funcionamiento organizacional en relación al reconocimiento, entendiendo éste como movimiento doble: atribución y adquisición a partir de la imagen proyectada. En este caso se pone especial 
atención a la contención emocional como un punto crítico de análisis sobre la manera de mostrarse ante compañeros y subordinados. Veamos:

"O sea, claro a lo mejor, pucha, lo único que quiero es irme, quiero irme para mi casa luego, pero no puedo bajar a formar con mis cadetes con la cara larga, porque ellos a uno lo tienen de ejemplo, o sea, como uno le va a decir a él, a ellos... <oiga, motivese, sea enérgica, no sé>...si uno está mal" (Cadete $3^{\circ}$ ).

Siguiendo a Martuccelli (2007) diremos que el cuidado del respeto en el régimen de interacción jerárquica está marcado por la preocupación última del honor. Es en este punto donde se encuentra el entramado simbólico y valórico con la posición en la estructura jerárquica, en tanto el valor representado por el honor, emerge como un efecto de posición "hay que poner al otro en su lugar, a fin de asegurar el suyo propio" (p.225). Ello apunta en un mismo movimiento a visibilizarlo para demandar el debido respeto y defenderlo, a fin de conservar la posición. "Es, entonces, en función de la jerarquia de las personas, que el individuo está obligado a hacerse respetar, a someterse a las ordenes debidas a un hombre de honor, de ser entonces, en el sentido más preciso del término, un verdadero sujeto moral que debe responder a todos sus gestos, actitudes y palabras" (p.225). Para Bourdieu (2005) lo que está detrás del honor, es la defensa del capital simbólico, esto es, poderes y derechos, tanto sobre las cosas como sobre las personas. Según el autor, en la dinámica social se producen unos signos de prestigio que, al ser intercambiados entre iguales producen una relación de honorabilidad equivalente, cuestión que funciona como condición de intercambio. Cualquiera que no caiga en este registro queda circunscrito a una relación de honorabilidad desigual, de dominación.

Recogiendo estas claves analíticas es posible interpretar que representar al sujeto militar involucra sostener un lugar de poder y control frente a las circunstancias, pero sobre todo, frente a los otros, de los que se espera adquirir una preeminencia relacional, es decir una posición de autoridad. Ello implica evitar que se trasluzcan, al momento de presentarse a las obligaciones demandadas por este sistema educativo, que les posiciona como "tutores" y "ejemplos a seguir", diferenciales que pudiesen surgir entre las vivencias y sentimientos interiores y el "personaje" dramatizado. Lo que podríamos interpretar como una proyección de una imagen de autoridad como una carta de funcionamiento organizacional. Se debe sostener el lugar reclamado, ponerse en altura, cumplir los parámetros, acatar la norma. En el contexto educativo militar toman fuerza las presiones situacionales que inscriben en una 
relación jerárquica a los capaces y a los otros. Los cadetes, pero principalmente las cadetes mujeres, circulan por la lógica del mantenimiento del honor, que les estimula a realizar actos de desafío para sostener el lugar reclamado. Así es como la autoridad, leída en clave de reconocimiento, implica en este caso, más para algunas que para otros, su desconocimiento.

La proyección de autoridad como una carta de funcionamiento organizacional toma forma en este contexto, como la restricción de emociones y sentimientos, asociados al desaliento, en la medida que producen descrédito y son interpretadas como desestabilizadoras de la imagen de autoridad y de la capacidad de ejercicio. Para evitar tal efecto, se requiere que las emociones puedan ser trasmutables en energía, particularmente aquellas vinculadas con la demostración de fortaleza. La organización propone un carácter único e idealizado de la autoridad, aquel que concuerda con patrones ideales de masculinidad. En este caso se impone una lectura desde la ideología de género, a través de la cual se naturalizan las características simbólicamente asociadas a lo femenino y a lo masculino. La autoridad desde este lugar solo puede ser autorizada y sostenida por hombres capaces de encarnar, por supuesto nunca a cabalidad, un ideal masculino.

\section{La autoridad como instrumento de dominación}

Desde la teoría de la dominación masculina Pierre Bourdieu (2005) nos entrega algunas claves para pensar la autoridad, no tanto para ajustar su definición como para indagar sobre sus efectos. Y en este sentido, lo pertinente es evidenciar los mecanismos de poder y dominación que subyacen a las relaciones de autoridad. Para Bourdieu, la dominación adopta una forma de violencia simbólica que opera en las prácticas que componen un habitus, éste se instituye incorporando a su vez la arbitrariedad del dominador en la forma de disposiciones.

En este tipo de análisis son la sumisión o la obediencia las demandas y respuestas que se obtienen de la relación, abandonándose las de reconocimiento y aceptación. La obediencia se inscribe como voluntaria en un contexto en que los individuos, tanto dominantes como dominados, están importantemente constreñidos por estructuras incorporadas que les impelen a reproducir a un 
modo inconsciente las jerarquías, aceptando su lugar en ellas y asegurando una cierta concepción del mundo.

En este marco de comprensión, la autoridad se confunde con el poder (dominación sobre) y por ello queda restringida a ser un instrumento que le confiere legitimidad.

Uno de los ejemplos privilegiados para mirar este fenómeno de dominación es la que se ejerce desde los hombres hacia las mujeres. La dominación masculina, y subordinación femenina, deben leerse en un contexto ideológico que toma por premisa una visión unitaria del mundo a través de oposiciones excluyentes. Como indica Sharim (2005) "Oposiciones que, siendo parecidas en la diferencia, son lo suficientemente concordantes para sostenerse mutuamente y, al mismo tiempo, son lo bastante divergentes como para conferir a cada cual una connotación valórica determinada" (p.28). En base a esta lógica se han construido lo masculino y lo femenino, asignando a cada parte de la "unidad" discursos valóricos que plasman la oposición, un ejemplo de ello es la valorización jerárquica entre sexo fuerte/sexo débil.

Bourdieu (2005) explica que los valores asignados, realmente, son esquemas prácticos de acción que "impone una definición diferenciada de los usos legitimos del cuerpo (...) para producir ese artefacto social llamado un hombre viril o una mujer femenina” (p.37). Para el autor, existe una relación dialéctica entre las preconcepciones que se anteponen a la distinción entre lo masculino y femenino, y las prácticas que éstos favorecen. La subordinación femenina responde al mantenimiento de una economía de los bienes simbólicos, donde las mujeres aparecen reducidas a objetos de intercambio, en tanto "los hombres producen unos signos y los intercambian activamente, como aliados-adversarios unidos por una relación esencial de honorabilidad equivalente, condición indispensable de un intercambio que puede producir un a honorabilidad desigual, es decir, la dominación" (p.62).

Autoridad y dominación: las posibilidades de ejercicio de la profesión

La Educación Militar propone, a grandes rasgos, tres especializaciones profesionales. La primera "armas" derivada de la figura del soldado que está en primera línea de combate, preparado técnica y físicamente en el saber 
específico de su profesión. La segunda, “armas de apoyo al combate”, que si bien se inserta en la categoría de las armas su ejercicio consiste en ocuparse de los aspectos logísticos necesarios para el combate. La tercera "servicios" anclada en las funciones administrativas para el mantenimiento diario y regular de la organización. Este apartado se ocupa de analizar cómo las cadetes interpretan para sí la profesión militar desde las trayectorias profesionales que deben y pueden optar, y como dentro de ello se manifiestan las constantes de género que limitan el ejercicio de la profesión.

El tercer y último escenario en el que analizó las posibilidades de ejercicio de la profesión, principalmente toca la exclusión de las mujeres de las actividades de combate directo. Esta normativa que manda a su alejamiento, es sostenida a partir de una cosmovisión tradicional de los roles de género, reproduciendo una autoridad masculina.

Los argumentos de autoridad de hombres sobre mujeres toman forma en una historia narrada -interesadamente- desde el punto de vista masculino, que permite finalmente establecer un carácter de verdad natural "lo que ya se sabe" a las creencias fundamentales de ésta comunidad. Como muestra uno de los relatos:

"Por ejemplo, a mi me gusta Caballeria Blindada, que es conducir tanques, pero esta netamente ligada a hombres producto de, siempre me han comentado que en caso de guerra sería bastante horrible ver a una mujer quemada dentro de un tanque, producto que puede ser la madre de alguien, o la esposa de alguien" (Cadete $4^{\circ}$ ).

La idea de que naturalmente existen ocupaciones y tareas distintas para hombres y mujeres, tiene como efecto mantener a las mujeres al margen de las actividades distintivamente masculinas y distintivas de la profesión militar. Sin el manejo del armamento, quedan a distancia del ejercicio del poder y del ejercicio de la profesión militar, sólo logrando una participación figurativa.

Vital es la separación entre lo público y lo privado como fundamento de la exclusión de las mujeres en las actividades de combate directo, al tiempo que para inclinar sus carreras hacia las armas de apoyo y la especialidad de servicio femenino. Como ya hemos advertido, las "armas" son los instrumentos que se conectan con el saber especializado de la profesión, y es la especialización (incluidas las de apoyo) que confiere el reconocimiento de la actividad, así como también las credenciales necesarias para hacerse parte del escenario "público" 
y productivo militar, una situación de conflicto bélico. Los "servicios", por su parte, responden a una necesidad de mantenimiento cotidiano, de reproducción. Estos antecedentes permiten establecer un paralelo entre la administración y reproducción que puede interpretarse y extenderse al trabajo de reproducción que han ejercido las mujeres en la esfera privada, por tantos años, invisibilizado. Por otra parte también se puede establecer cómo se activa una estrecha relación entre las tareas administrativas - de funcionamiento y mantenimiento- y las tareas domésticas - de nutrición y abastecimiento. La extensión de roles feminizados junto a la orientación hacia especialidades subordinadas alejan a las mujeres del reconocimiento público y social, y de lo que significa e implica la practica militar, en tanto lo realmente militar parece estar, por un lado, en el ámbito de lo público -la guerra como el escenario productivo-y por otro, significando el ejercicio, el enfrentamiento, como lo activo, las mujeres quedan situadas en el espacio privado, al estar excluídas.

Estas lecturas que encuentran congruencia entre las asignaciones simbólicas a lo femenino y masculino, junto a las capacidades físicas de los cuerpos de las mujeres, se enmarcan en una historia narrada desde el punto de vista masculino que refuerza conductas, y establece argumentos de autoridad de los hombres sobre las mujeres, al punto que su exclusión, de las actividades de combate directo, casi prescinde de cualquier justificación.

La lógica que subyace a su exclusión no se encuentra en debilidades físicas ni psicológicas, responde, como explica tan claramente Bourdieu (2005), a que las cadetes adecuan sus esperanzas a las posibilidades reales demarcadas por la lógica de los sexos, éste es un trabajo que han realizado durante toda su experiencia como mujeres, y que permite desinhibir, desviar y ni siquiera plantearse aquellas actividades que no corresponden a las mujeres.

En este registro autoridad y dominación conviven gracias a dos mecanismos que lo permiten. El primero de ellos que he llamado naturalización del mito, a nivel discursivo y representacional alude a simbolizar doblemente a las mujeres. De alguna manera, se trata de vitalizar como sustento de exclusión, aquel imaginario que representan a las mujeres como peligrosas por un lado, y frágiles por otro. El segundo mecanismo que he llamado negación de las individualidades, actúa a nivel relacional. Las mujeres están inscritas en una versión universal y esencialista de la mujer. Son cuerpos indiferenciados remitidos a los papeles sociales de género, intercambiablescomo madres, esposas, 
hijas. Indiferenciación y negación que, por cierto, les impide a priori cualquier capacidad de elección y les mantiene en una situación de dominadas.

Reflexiones finales

Hasta aquí lo expuesto es un intento por salir del clásico análisis que se hace de la autoridad en este tipo de organizaciones, aquel que pone en el centro mando y obediencia. Apelando, quizás, a maneras menos exploradas de leer la autoridad en los distintos registros de esta particular experiencia.

Retomar la idea de que la autoridad esta mediada por distintos ámbitos sociales que le nutren y proveen de contenido vitalizando su significación, contribuye a entender que la autoridad puede ser una clave interpretativa, sin perder de vista las relaciones mando- obediencia, y nos habilita para realizar otros análisis que matizan la reflexión del fenómeno.

En este propósito hemos expuesto cómo la autoridad es posible de verificar en el tiempo biográfico, una lectura de la autoridad-autorización en la trama del tiempo histórico-social, siguiendo la propuesta de Myriam Revault. Mientras en unos casos el pasado familiar autoriza el presente de la acción en base a una herencia que es preciso reivindicar, en otras experiencias se actualiza y modula en la decisión-acción una preeminencia venida desde el futuro que al tiempo que autoriza las acciones presentes manda a autorizarse por sí mismo.

Por otra parte, parece interesante señalar una paradoja que se suscita en referencia a la autoridad con la entrada de las mujeres a la organización militar como parte de la fuerza. Mientras la tradición de excluir a las mujeres de las organizaciones militares ya no tiene vigencia, y por tanto la autoridad en tanto tradición se debilita en relación a ésta convención social, al mismo tiempo, este suceso abre la posibilidad a las mujeres de la familia de reproducir éste lazo entre las generaciones. En breve: la desconvencionalización a un nivel institucional (intermedio) fomenta la tradicionalización a un nivel micro (familiar) expandiendo su base.

De todos modos la autoridad en cualquiera de las direcciones que se ha enunciado puede ser caracterizada por su capacidad generativa, en palabras de la autora, es "condición de nuestros comienzos y de nuestras iniciativas: a la vez obligación heredada y recurso para la acción que se inicia” (p.73). 
Siguiendo lo señalado por la autora se expresa como poder neutro, latente y preservador, que no consiste en una actividad imperante ni reglamentadora, sino fundamentalmente en una actuación mediadora y tutelar.

Para el segundo escenario que hemos planteado -la permanencia- si resumiéramos lo que el respeto a la autoridad estatuida por la jerarquía ligada a una estructura particularmente abrumadora nos propone acerca de la autoridad, es que se contraviene el fundamento de la autoridad sustentada sólo en la posición que manda a obedecer, principalmente porque la jerarquía necesita llenarse de otros contenidos, como es el de precedencia, a fin de no abrir el flanco a una autoridad que se apoya de modo autoritativo y se ejercite como sometimiento activando con toda contundencia el poder y la arbitrariedad.

En relación a la proyección y reconocimiento de una imagen de autoridad como una carta de funcionamiento organizacional, esta entrada muestra cómo el reconocimiento se traduce en autocontrol. En este caso, existe un movimiento de afirmación que es proyectado desde el interior, siguiendo las pautas establecidas en el sistema, para someterse a juicio.

Finalmente para el tercer escenario -las posibilidades de ejercicio- hemos vuelto la mirada a una manera menos precisa para leer la autoridad, pero que permite ver sus efectos y los mecanismos que la soportan. Así planteamos que las cadetes son "victimas" de la violencia simbólica (Boudieu, 2005) operada en la congruencia entre las asignaciones simbólicas tradicionales a lo femenino, la generalización de las capacidades físicas atribuidas a los cuerpos de mujeres, y su intercambiabilidad con los papeles sociales de género, que solapadamente se ponen en funcionamiento, a partir de dos mecanismos para excluir a las mujeres de las actividades de combate directo y mantenerles en la inercia de las cosas, lo naturalizado, lo objetivado. En este marco de comprensión, importantemente guiado por la idea de sumisión, la autoridad se confunde con el poder y por ello queda restringida a ser su instrumento.

Estos tres escenarios estudiados junto a tres miradas para interpretar la autoridad, no son necesariamente excluyentes así como tampoco complementarios. En esta línea, cada perspectiva es retomada para diferentes niveles analíticos para un fenómeno complejo como es la integración de mujeres al Ejército de Chile. En este sentido, cada mirada haya su valor en mostrar las distintas formas en que se movilizan las relaciones de autoridad y los diversos sostenes en que se afirma, los que deben son especificados, como hemos mostrado, a la luz de los contextos en que surgen, pero también, en 
relación a la perspectiva de género. Particularmente, nuestro análisis tiene como base la experiencia de mujeres en organizaciones militares, organizaciones cuya función ha sido ejercida históricamente sólo por varones, por lo cual ha desarrollado prácticas, lenguajes y códigos que la hacen institucionalmente masculina. 


\section{Referencias bibliográficas}

Araujo, K. (2012). The Belief in Legitimacy: Social Experiences and the Relationship from Individuals to Norms. En A. Mascareño y K. Araujo, K. (eds.) Legitimization in the world society. pp. 157-175. London: Ashgate.

Arendt, H. (1996). Entre el pasado y el futuro, ocho ejercicios sobre la reflexión política. [1968] Madrid: Península.

Bourdieu, P. (2005). La dominación masculina. Barcelona: Anagrama.

Gadamer, H.G. (1997). Verdady Método. Salamanca: Ediciones Sígueme.

Geicsnek, E. (2012). Comunidad, autoridad y orden social en Max Weber y Emile Durkheim. En: de Marinis, P. (Coord). Comunidad: Estudios de teoría sociológica. Buenos Aires: Editorial Prometo. pp 67-106.

Kojève, Alexandre (2006). La noción de autoridad. Buenos Aires: Nueva Visión.

Lucero, M.R. (2009). Las mujeres en las fuerzas armadas argentinas. Breve análisis sobre su participación y estado actual de la situación. UNISCI Discussion Papers, n. ${ }^{\circ}$ Mayo, pp. 36-49.

Martucelli, D. (2007). Gramáticas del individuo. Buenos Aires: Editorial Losada.

Ministerio de Defensa Nacional de Chile. (2005). Libro de Defensa Nacional: Separata de actualización 28: Participación de las mujeres en las Fuerzas Armadas. Santiago: Ministerio de Defensa Nacional de Chile.

Molina L. y J. F. (1996). Quintas y servicio militar: Aspectos sociológicos y antropológicos de la conscripción (Lleída 1878-1960). Tesis doctoral Universitat de Lleída, España.

Moskos, C. (1982). La nueva organización militar: ¿Institucional, ocupacional o plural?, en: Conferencia de Inauguración de las II jornadas de Sociología de la Asociación Castellana de Sociología. Madrid, pp. 297-306.

PNUD. (2010). Desarrollo Humano en Chile. Género: Los desafíos de la 
igualdad. Santiago: PNUD.

Renaut, A. (2004). La fin de l'autorité. Francia: Flammarion.

Revault D’ Allonnes. M. (2008). El poder de los comienzos. Ensayo sobre la autoridad. Buenos Aires: Amorrortu.

Sharim, D. (2005). Identidad y roles de género. Una aproximación desde los relatos de vida. Tesis doctoral en Sciences Psychologiques. Bélgica.

Vieytes R. (2004). Metodología de la investigación de las organizaciones, mercado y sociedad. Epistemología y técnicas. Buenos Aires: Editorial de las Ciencias.

Weber, M. (1964). Economia y Sociedad. México: FCE. 